\title{
THE IMPACT OF THE VARIABILITY OF PRECIPITATION AND TEMPERATURES ON THE EFFICIENCY OF A CONCEPTUAL RAINFALL-RUNOFF MODEL
}

\author{
P. SLEZIAK ${ }^{1 *}$, J. SZOLGAY ${ }^{1}$, K. HLAVČOVÁ ${ }^{1}$, J. PARAJKA ${ }^{2,3}$
}

\section{Abstract}

The main objective of the paper is to understand how the model's efficiency and the selected climatic indicators are related. The hydrological model applied in this study is a conceptual rainfall-runoff model (the TUW model), which was developed at the Vienna University of Technology. This model was calibrated over three different periods between 1981-2010 in three groups of Austrian catchments (snow, runoff, and soil catchments), which represent a wide range of the hydroclimatic conditions of Austria. The model's calibration was performed using a differential evolution algorithm (Deoptim). As an objective function, we used a combination of the Nash-Sutcliffe coefficient (NSE) and the logarithmic Nash-Sutcliffe coefficient (logNSE). The model's efficiency was evaluated by Volume error (VE). Subsequently, we evaluated the relationship between the model's efficiency (VE) and changes in the climatic indicators (precipitation $\Delta P$, air temperature $\Delta T$ ). The implications of findings are discussed in the conclusion.
Address

1 Department of Land and Water Resources Management, Faculty of Civil Engineering, Slovak University of Technology, Bratislava, Slovakia (patrik.sleziak@stuba.sk, jan.szolgay@stuba. sk, kamila.hlavcova@stuba.sk)

2 Institute of Hydraulic Engineering and Water Resources Management, Vienna University of Technology, Vienna, Austria

3 Centre for Water Resource Systems, Vienna University of Technology, Vienna, Austria (parajka@hydro.tuwien.ac.at)

* Corresponding author: patrik.sleziak@stuba.sk

\section{Key words}

- TUW model,

- Model's efficiency,

- Nash-Sutcliffe coefficient,

- Logarithmic Nash-Sutcliffe coefficient

\section{INTRODUCTION}

Conceptual rainfall-runoff models are frequently used to assess and evaluate the effect of climate change on water resources. A difficult as well as debated issue is the effciency of these models in different climatic periods. One of the possible approaches for evaluating a model's efficiency in contrasting time periods is to apply the Differential Split-Sample Test (DSST). The principle of DSST is that the data split into various calibration and validation periods based on their climatic differences (Klemeš, 1986). Most authors who use the DSST have identified a significant decreasing trend in the model's efficiency over time (Wilby, 2005; Vaze et al., 2010; Merz et al., 2011; Bai et al., 2015; Fowler et al., 2016). In this context, several authors have also showed that the model's efficiency can be associated with changes in the climatic indicators (e.g., Oudin et al., 2006; Vaze et al., 2010; Coron et al., 2012; Bai et al., 2015; Magand et al., 2015). Oudin et al. (2006) analyzed the efficiency of two lumped rainfall-runoff models (GEJ4 and TOPMODEL) in contrasting periods. The authors in their study showed that the precipitation had a large impact on the model's efficiency. A similar analysis was carried out by Vaze et al. (2010). They used four rainfall-runoff models on a set of 61 catchments in Austalia and evaluated their efficiency. They concluded that the efficiency of these models was associated with changes in the climatic indicators of the calibration periods. The work of Bai et al. (2015) should also be mentioned. In their study the authors compared the efficiency of 12 hydrological models in different time periods for 153 catchments in China. They found that the climatic characteristics (mainly aridity) and the catchment characteristics (mainly the area) had the largest impact on the model's efficiency. Magand et al. (2015) used a physically-based Catchment Land Surface Model (CLSM) in the Durace catchment in France and analyzed its efficiency. In their study the authors showed that the model's efficiency was affected by 
climatic characteristics. This is also in line with the analysis of Coron et al. (2012), who used three lumped rainfall-runoff models (GRJ4, MORDOR6, SIMHYD) on 216 catchments in Australia. They found that the model's efficiency was influenced by changes in the precipitation.

Most of these studies showed that climatic characteristics can influence a model's efficiency, but the results of Lay et al. (2007) contrast with these findings. They used various hydrological models in different catchments in Africa. According to their study, there was no relationship between a model's efficiency and the climatic indicators. Therefore, this paper recognizes that the efficiency of hydrological models in different climatic periods is still not straightforward and that further investigation is needed. The aim of this paper is to understand how a model's efficiency and the selected climatic indicators are related.

This paper is organized as follows: The data (213 Austrian catchments) are presented in Section 2. The rainfall-runoff model is described in Section 3 and followed by the calibration and validation strategy in Section 4. The relationship between the model's efficiency and the climatic indicators is presented in Section 5. The results and discussion are given in Section 6. Finally, the conclusions are summarized in Section 7.

\section{DATA}

We used a sample of 213 Austrian catchments (Fig. 1), which cover a wide range of physiographic conditions (different areas, elevations, slopes, and geology) and hydroclimatic conditions (different precipitation and air temperatures) (Gaál et al., 2012). The data were available for the 1981-2010 period and consisted of the daily precipitation, air temperature, potential evapotranspiration, and streamflow. The catchment area ranges from approximately 15 to around 6200 $\mathrm{km}^{2}$. The elevation ranges from 100 to $3300 \mathrm{~m}$ a.s.l. The mean annual precipitation among the catchments ranges from 400 to $3000 \mathrm{~mm} /$ year. The mean annual air temperature varies from 8 to $10^{\circ} \mathrm{C}$.

Firstly, we classified the catchments into three groups: snow, runoff, and soil (Fig. 1). This classification was performed with respect to the objective function. From Fig. 1 we can see that the snow group of catchments is located in the western part of Austria. In this part of the region the hydrological regime is influenced by snow. The runoff group of catchments is located in the southern part of Austria, and the soil group of catchments is located in the northeastern part of Austria. In this part of the region the hydrological regime is influenced by rainfall.

The character of the specified calibration periods (1981-1990, 1991-2000, 2001-2010) was documented using climatic characteristics such as the mean monthly precipitation $(\mathrm{P})$, temperature $(\mathrm{T})$, and streamflow $(\mathrm{Q})$ over the different groups of catchments (the snow, runoff, and soil groups) (Fig. 2). The graphs illustrate how variable the climate could be during the three periods. This is also shown in Tab. 1, which gives information about the mean monthly values of the climatic indicators averaged over three periods. From Fig. 2 we can see that the mean monthly precipitation $(\mathrm{P})$ of the snow catchments varies between $124-125-126 \mathrm{~mm} /$ month (top left); the $\mathrm{P}$ of the runoff catchments varies between $109-113-113 \mathrm{~mm} / \mathrm{month}$ (top middle), and the $\mathrm{P}$ of the soil catchments varies between $90-96-98$ $\mathrm{mm} /$ month (top right). We can observe that $\mathrm{T}$ increased on average by $0.5^{\circ} \mathrm{C}$ in the snow catchments, by $0.6{ }^{\circ} \mathrm{C}$ on average in the runoff catchments, and by $0.4{ }^{\circ} \mathrm{C}$ on average in the soil catchments. Q was constant over the three periods, but there are differences between the various groups of catchments (the $\mathrm{Q}$ of the snow catchments varies between $113-116-113 \mathrm{~mm} / \mathrm{month}$, the $\mathrm{Q}$ of the runoff catchments varies between $74-76-75 \mathrm{~mm} / \mathrm{month}$, and the $\mathrm{Q}$ of the soil catchments varies between $47-49-49 \mathrm{~mm} /$ month).

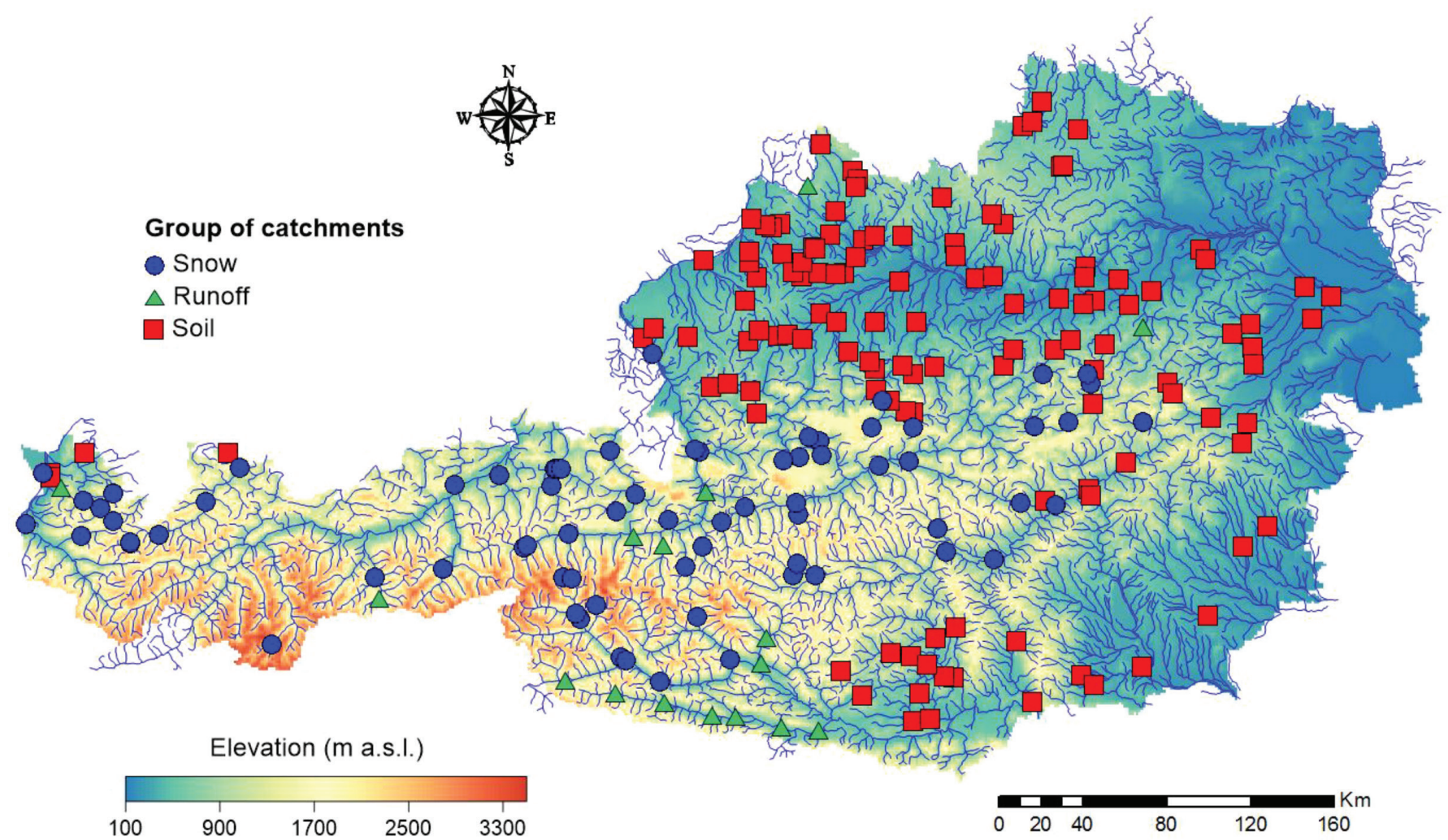

Fig. 1: Map of Austria with the selected gauging stations. The circles, squares and triangles indicate the different groups of catchments: the snow group (blue), runoff group (green), and soil group (red). The legend shows the ranges of the elevations. 

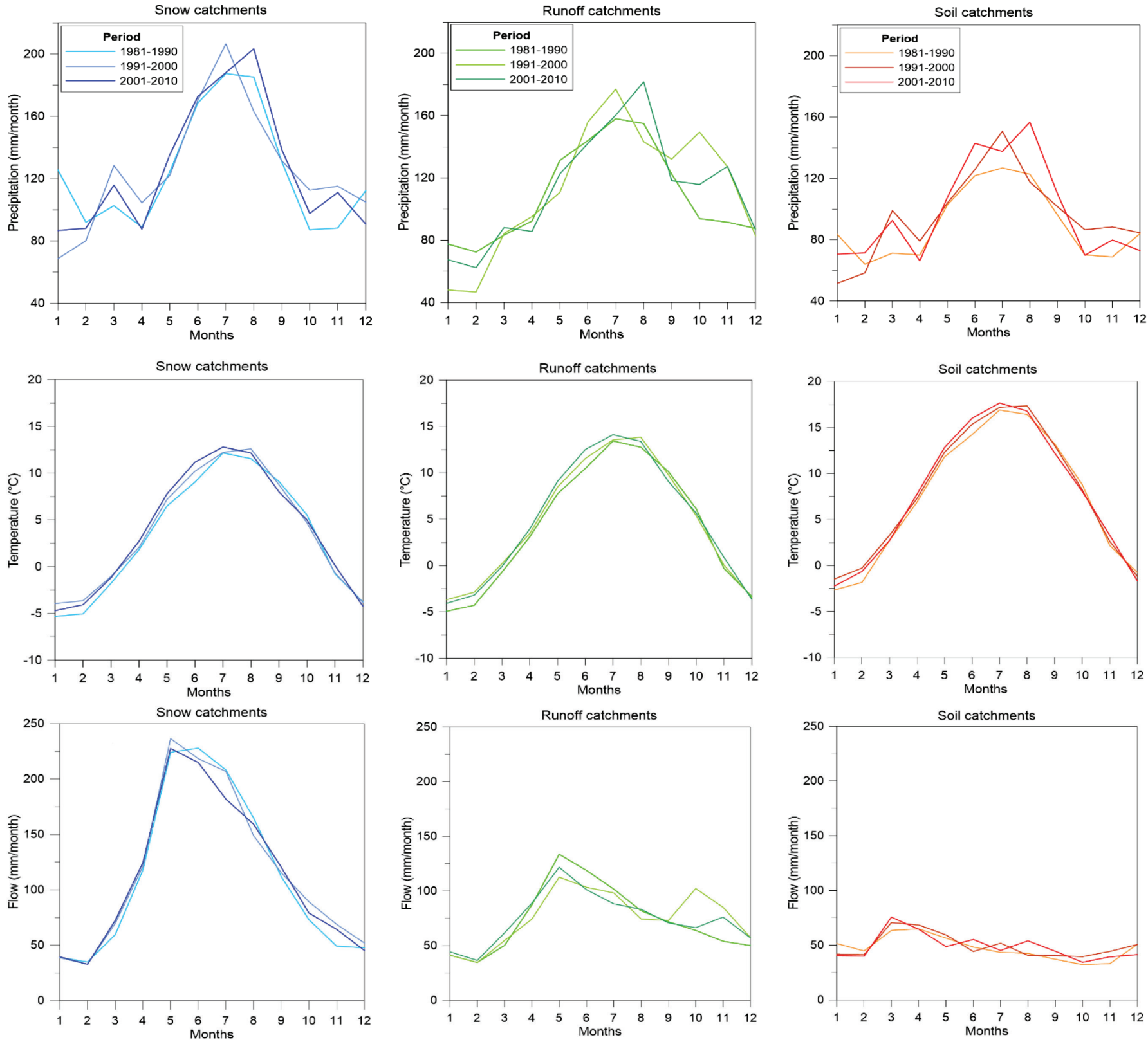

Fig. 2: Variabilty of the mean monthly precipitation, air temperature, and streamflow over the contrasting groups of Austrian catchments.

Tab. 1: Values of the mean monthly precipitation $(P)$, air temperature $(T)$ and streamflow $(Q)$ averaged over the specified periods for the different Austrian catchments.

\begin{tabular}{|c|c|c|c|}
\hline $\mathbf{P}(\mathrm{mm} / \mathrm{month})$ & $1981-1990$ & $1991-2000$ & $2001-2010$ \\
\hline Snow & 124 & 125 & 126 \\
\hline Runoff & 109 & 113 & 113 \\
\hline Soil & 90 & 96 & 98 \\
\hline $\mathbf{T}\left({ }^{\circ} \mathrm{C}\right)$ & $1981-1990$ & $1991-2000$ & $2001-2010$ \\
\hline Snow & 3.3 & 3.7 & 3.8 \\
\hline Runoff & 4.2 & 4.7 & 4.8 \\
\hline Soil & 7.3 & 7.8 & 7.7 \\
\hline$Q$ (mm/month) & $1981-1990$ & $1991-2000$ & $2001-2010$ \\
\hline Snow & 113 & 116 & 113 \\
\hline Runoff & 74 & 76 & 75 \\
\hline Soil & 47 & 49 & 49 \\
\hline
\end{tabular}




\section{RAINFALL-RUNOFF MODEL}

The model applied in this study is a lumped conceptual rainfall-runoff model (the TUW model) (Viglione and Parajka, 2014), which follows the structure of the HBV model (Bergström, 1995). The inputs to the model consist of daily series of percipitation, air temperature, evapotranspiration, and streamflow. The TUW model has 15 parameters, the values of which are described in Tab. 2. The structure of the model involves three components: snow, soil moisture, and runoff submodels (Merz and Blöschl, 2004). More details about the concept of the model can be found in Parajka et al. (2007).

Tab. 2: Description of the model parameters with their boundaries ( $T$ - air temperature, $P$ - precipitation, EP-potential evapotranspiration).

\begin{tabular}{lll}
\hline $\begin{array}{l}\text { Model } \\
\text { parameter }\end{array}$ & Definition and units & Range \\
SCF & snow correction factor $(-)$ & $0.9-1.5$ \\
$\mathrm{DDF}$ & degree-day factor $\left(\mathrm{mm} /{ }^{\circ} \mathrm{C}\right.$ day) & $0-5$ \\
$\mathrm{Tr}$ & threshold T above $\mathrm{P}$ is rain $\left({ }^{\circ} \mathrm{C}\right)$ & $1-3$ \\
$\mathrm{Ts}$ & threshold T below P is snow $\left({ }^{\circ} \mathrm{C}\right)$ & $-3-1$ \\
$\mathrm{Tm}$ & threshold T above which snow melts start $\left({ }^{\circ} \mathrm{C}\right)$ & $-2-2$ \\
LPrat & parameter related to the limit for EP $(-)$ & $0-1$ \\
FC & maximum soil moisture storage (mm) & $0-600$ \\
BETA & nonlinearity parameter of runoff generation $(-)$ & $0-20$ \\
k0 & storage coefficient of additional outlet (day) & $0-2$ \\
k1 & fast storage coefficient (day) & $2-30$ \\
k2 & slow storage coefficient (day) & $30-250$ \\
lsuz & threshold storage state (mm) & $1-100$ \\
cperc & constant percolation rate (mm/day) & $0-8$ \\
bmax & maximum base at low flows (day) & $0-30$ \\
croute & free scaling parameter (mm/day) & $0-50$ \\
\hline
\end{tabular}

\section{CALIBRATION AND VALIDATION}

The calibration and validation strategy implemented in this study is based on the Differential Split-Sample Test (DSST). The principle of this test is based on splitting periods into sub-periods, which show climatic contrasts (Klemeš, 1986). We used this test over three different periods between 1981-2010 for 213 Austrian catchments (the catchments are divided into 3 groups: snow, runoff, and soil groups) The objective function used in the calibration consisted of a combination of the Nash-Sutcliffe coefficient (NSE) (Nash and Sutcliffe, $1970)$ and the logarithmic Nash-Sutcliffe coefficient $(\log N S E)$ (Merz et al., 2011). This objective function was minimized by a differential evolution algorithm (Deoptim) (Swagatam, 2011).

The model's efficiency was evaluated by the volume error $(V E)$, which was calculated as follows:

$$
V E=\frac{\sum_{i=1}^{n} Q_{s i m}^{i}-\sum_{i=1}^{n} Q_{o b s}^{i}}{\sum_{i=1}^{n} Q_{o b s}^{i}}
$$

Where $Q_{s i m}^{i}$ and $Q_{o b s}^{i}$ are the observed and simulated flows, $V E$ $=0$ indicates that there were no changes between the observed and simulated flows; $V E>0$ and $\mathrm{VE}<0$ indicate overestimated and underestimated flows. Fig. 3 provides information about the plotting of the volume error values $(V E)$ for the specified calibration and valida-

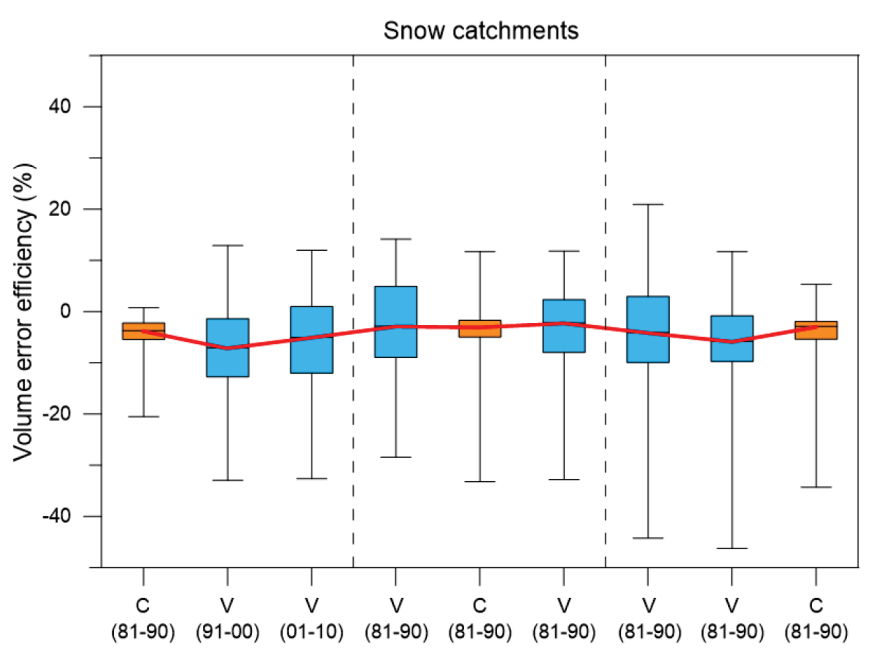

Calibration and validation periods (years)
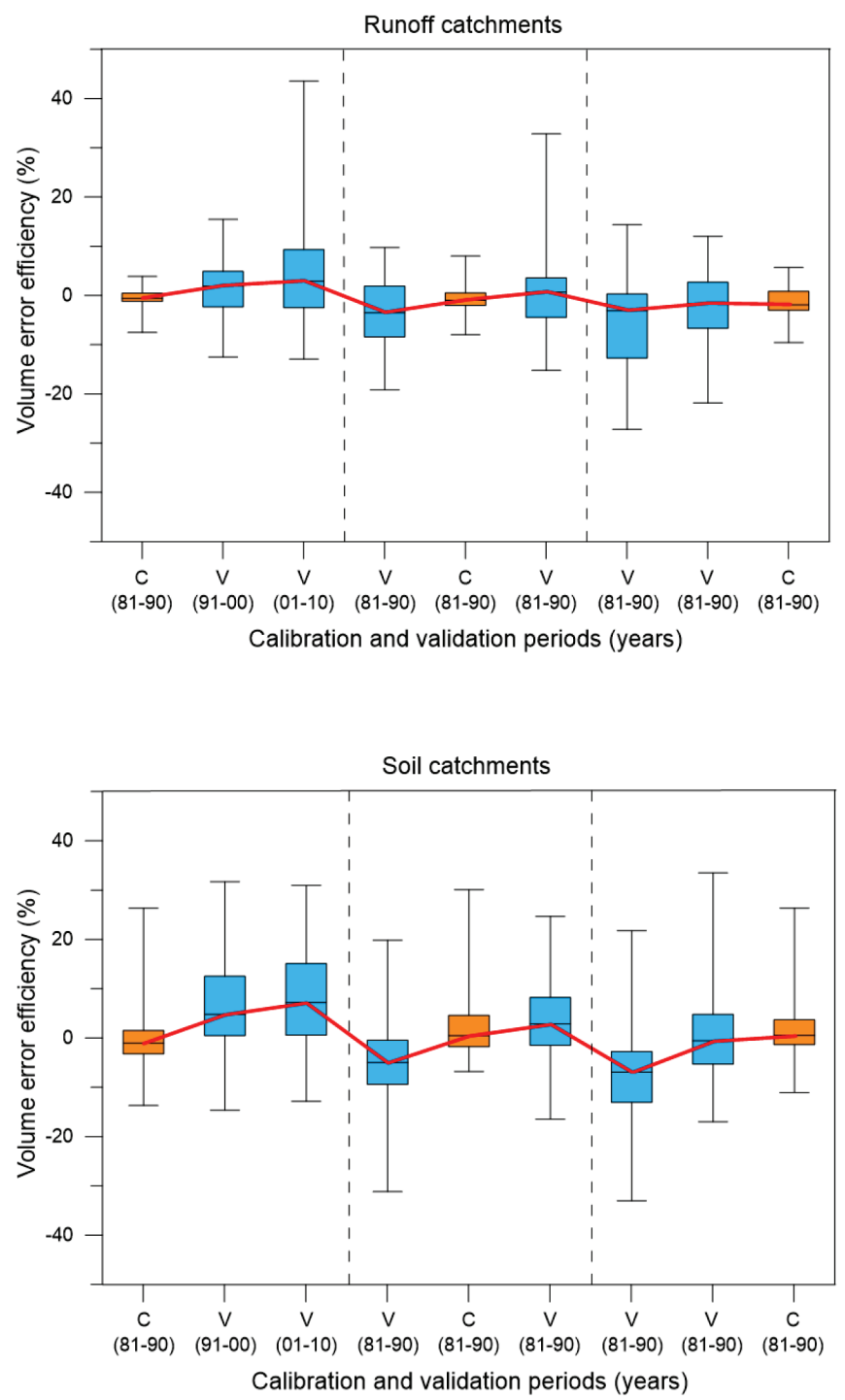

Fig. 3: Comparison of the variability of the VE values for all the calibration and validation periods (the orange box-plots represent the calibration periods; the blue box-plots represent the validation periods. The red line shows the median of the VE, C-Calibration, $V$ - Validation). 
tion periods. From these graphs it is clear that the $V E$ in the specified calibration and validation periods has changed over time. This is also documented in Tab. 3, which gives information about the mean values of $V E$. From Tab. 3 we can see that the mean values of $V E$ over the snow catchments in the specified calibration periods were as follows: $-4 \%,-4 \%$, and $-5 \%$. We can also observe a similar trend in the negative values of $V E$ over the runoff catchments in the calibration periods ( $V E$ in a range of $-0.3 \%,-0.4 \%$, and $-1 \%$ ). These negative values ( $V E$ $<0)$ indicate a trend of underestimating flows in these periods. To the contrary, the $V E$ over the soil catchments in the calibrations were on average $-0.4 \%$ (1981-1990), 2\% (1991-2000), and 2\% (2001-2010). We can see that the validation $V E$ in 1981-1990 are about -4\% (snow catchments), $-4 \%$ (runoff catchments), and $-7 \%$ (soil catchments) when using the model parameters calibrated to the most recent years (2001-2010). From this analysis it is clear that the parameters from 2001-2010 underestimate the flows in the other years (1981-1990).

Tab. 3: The mean values of the VE (\%) in the specified calibration and validation periods.

\begin{tabular}{|c|c|c|c|}
\hline Group of catchments & C (81-90) & V (91-00) & $V(01-10)$ \\
\hline Snow & -4.4 & -6.7 & -5.7 \\
\hline Runoff & -0.3 & 1.8 & 3.9 \\
\hline Soil & -0.4 & 6.6 & 8.3 \\
\hline Group of catchments & V (81-90) & C (91-00) & V (01-10) \\
\hline Snow & -2.3 & -4.2 & -2.9 \\
\hline Runoff & -3.7 & -0.4 & 0.8 \\
\hline Soil & -4.9 & 1.9 & 3.6 \\
\hline Group of catchments & $V(81-90)$ & V (91-00) & C (01-10) \\
\hline Snow & -4.3 & -6.1 & -4.7 \\
\hline Runoff & -4.2 & -2.1 & -1.1 \\
\hline Soil & -7.1 & -0.3 & 1.9 \\
\hline
\end{tabular}

\section{THE RELATIONSHIP BETWEEN THE MODEL'S EFFICIENCY AND CHANGES IN THE CLIMATIC INDICATORS}

The relationship between the model's efficiency in the validation and the changes in the climatic indicators (mean annual precipitation $\Delta \mathrm{P}$, mean annual air temperature $\Delta \mathrm{T}$ ) is presented below. This can be seen in Fig. 4, which gives information about the median value of $V E$. When we compare the results from all three groups of catchments (snow, runoff, and soil groups) (Fig. 4), we see a similar pattern in $\triangle \mathrm{P}$, which was reflected in $V E$, which means that the $V E$ was mainly affected by $\Delta \mathrm{P}$. In other words, when the $\Delta \mathrm{P}$ was higher, the $V E$ reached higher values (the blue colour in the legend). This trend was clearer for the soil catchments (Fig. 4, bottom). For example, in soil group of catchments (Fig. 4, bottom), when $\Delta \mathrm{P}=5-30 \%$ and $\Delta \mathrm{T}$ $=0-1{ }^{\circ} \mathrm{C}$, the $V E$ reached higher values $(15-30 \%, V E>0$ indicate overestimated flows). On the contrary, when the $\Delta P$ was lower, the $V E$ reached lower values (the red colour in the legend). For example, in snow group of catchments (Fig. 4, top), when $\Delta \mathrm{P}=0 \%$ and $\Delta \mathrm{T}=$ $1.5-2{ }^{\circ} \mathrm{C}$, the $V E$ reached lower values (from -15 to $-30 \% ; V E<0$ indicates underestimated flows). In this group of catchments also $\Delta \mathrm{T}$ had a significant effect on the $V E$. From these findings it is clear that the VE was affected by the changes in the climatic indicators $(\triangle \mathrm{P}$, $\Delta \mathrm{T})$. We can also conclude that changes in $\mathrm{P}(\Delta \mathrm{P})$ influenced the $V E$ more than changes in $\mathrm{T}(\Delta \mathrm{T})$.
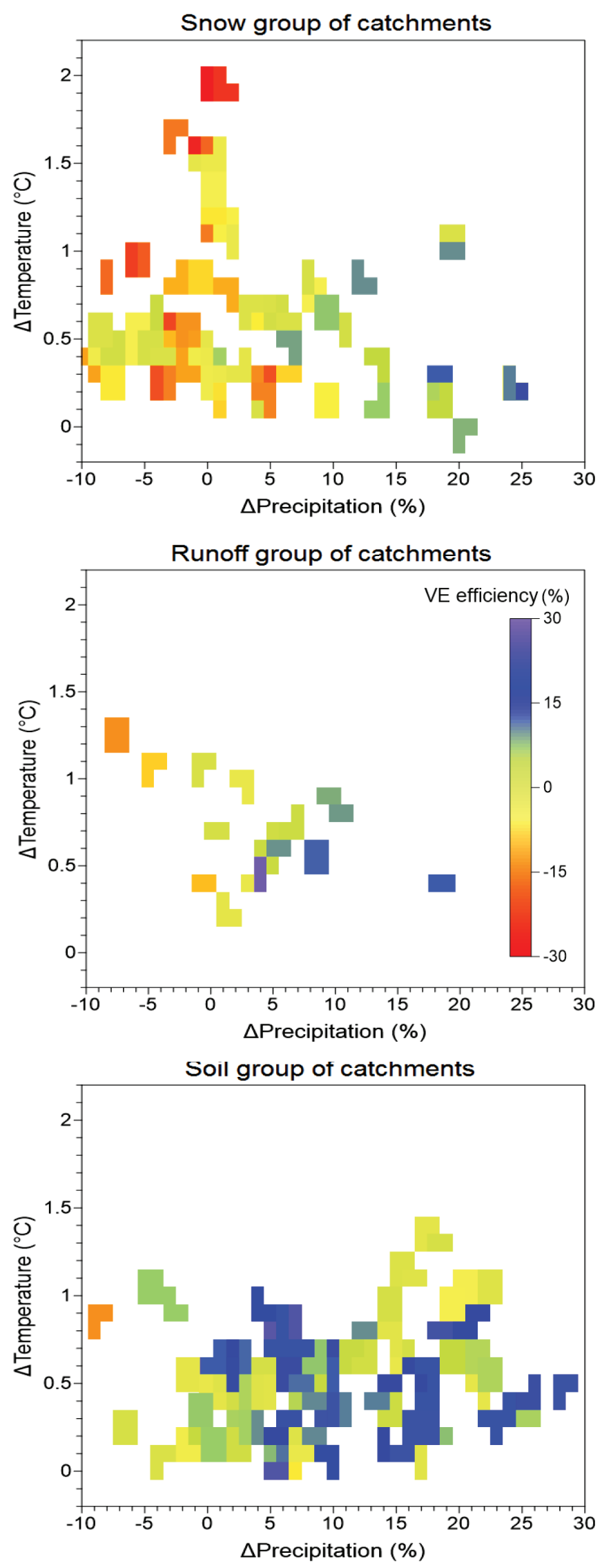

Fig. 4: Relationship between the changes in the climatic indicators and the model's effciency. The changes $(\triangle P, \Delta T)$ are defined as the differences between the third period (2001-2010) and the first period (1981-1990). 


\section{RESULTS AND DISCUSSION}

The results show that more changes in the model's efficiency concerning the different groups of Austrian catchments over time have been identified. According to Fig. 3, which provides information about the comparison of the variability of the $V E$ values for the specified calibration and validation periods, we found a tendency to underestimate the flows $(V E<0)$ when the model parameters were optimized in more recent years (2001-2010). In other words, the validation $V E$ in 1981-1990 was about $-4 \%$ (snow group of catchments), $-4 \%$ (runoff group of catchments), and $-7 \%$ (soil group of catchments), when we used parameters calibrated to the most recent years (2001-2010). This is also in line with the analysis of Merz et al. (2011), where the authors showed similar findings. Subsequently, we analyzed the relationship between the model's efficiency $(V E)$ in the validation and the changes in the climatic indicators $(\Delta P, \Delta T)$. According to Fig. 4, which provides information about the plotting of the relationship between the changes in climatic indicators $(\triangle P, \Delta T)$ and the model's efficiency $(V E)$ in the validation, we found that the model's efficiency was mainly influenced by changes in precipitation $(\triangle P)$. This means that the climatic indicators had an impact on the model's efficiency. These results corroborate the findings of Oudin et al. (2006) and Coron et al. (2012), who observed a significantly increasing trend in $\mathrm{P}$, which corresponded to an increasing trend in the $V E$.

\section{CONCLUSION}

Hydrological models are useful and robust tools for assessing the effect of climate change on water regimes. The efficiency of these models in contrasting climate periods is a frequent topic among researchers throughout the world. In this paper we investigated the model's efficiency in different climate periods. In the first part of the study we evaluated the model's efficiency in terms of volume error $(V E)$. We found a tendency to underestimate flows $(V E<0)$ when the model parameters were optimized in more recent years (2001-2010). This means that the parameters from more recent years (2001-2010) underestimate the flows in other years (1981-1990). Later in this article we focused on analyzing the relationship between the model's efficiency in the validation and the changes in the climatic indicators $(\Delta P, \Delta T)$. The results showed that the model's efficiency was mainly affected by changes in precipitation $(\Delta P)$ (when $\Delta \mathrm{P}$ was higher, the $V E$ reached higher values and conversely). This means that the climatic indicators had an impact on the model's efficiency.

These results have implications when using rainfall-runoff models as tools in practical applications, for example, flood protection, flood forecasting, hydropower, and climate change studies, etc. As a result, we also recommend applying similar or new testing approaches with other models at different catchments (energy limited/water limited).

\section{Acknowledgements}

This work was supported by the Slovak Research and Development Agency under Contract No. APVV-15-0425 as well as VEGA Grant No. 1/0710/15. The authors gratefully acknowledge the support from the National Scholarship Programme of the Slovak Republic. 


\section{REFERENCES}

Bai, P. - Liu, X. - Lian, K. - Liu, X. (2015) Comparison of performance of twelve monthly balance models in different climatic catchments of China. Journal of Hydrology, 529, pp. 1030-1040. Doi: 10.1016/j.jhydrol.2015.09.015.

Bergström, S. (1995) The HBV model. Computers Models of Watershed Hydrology, edited by V.P. Sing, Water. Resour. Publ., pp. 443-476.

Coron, L. - Andréassian, V. - Perrin, C. - Lerat, J. - Vaze, J. - Bourqui, M. - Hendrickx, F. (2012) Crash testing hydrological models in contrasted climate conditions: An experiment on 216 Australian catchments. Water Resour. Res., 48, W05552. Doi: 10.1029/2011WR011721.

Fowler, K. J. A. - Peel, M. C. - Western, A. W. - Zhang, L. Peterson, T. J. (2016) Simulating runoff under changing climatic conditions: Revisiting an apparent deficiency of conceptual rainfall-runoff models. Water Resour. Res., 52, pp. 1820-1846. Doi:10.1002/2015WR018068.

Gaál, L. - Szolgay, J. - Kohnová, S. - Parajka, J. - Merz, R. - Viglione, A. -Blöschl, G. (2012) Flood timescales: Understanding the interplay of climate and catchment processes through comparative hydrology. Water. Resour. Res. 48, W0451. Doi: 10.1029/2011WR011509.

Klemeš, V. (1986) Operational testing of hydrological simulation models. Hydrol. Sci. J., 31(1), pp. 13-24. Doi:10.1080/02626668609491024.

Le Lay, M. - Galle, S. - Saulnier, G. M. -Braud, I. (2007) Exploring the relationship between hydroclimatic stationarity and rainfall-runoff model parameter stability: A case study in West Africa. Water Resources Research 43, W07420. Doi: 10.1029/2006WR005257.

Magand, C. - Ducharne, A. - Moine, N. - Brigode, P. (2015) Parameter transferability under changing climate: case study with a land surface model in the Durance watershed France. Hydrological Sciences Journal, 60:7-8, pp. 1408-1423. Doi: 10.1080/02626667.2014.993643.
Merz, R. - Parajka, J. - Blöschl, G. (2011) Time stability of catchment model parameters: Implication for climate impact analyses. Water Resour. Res., 47, W02531. Doi: 10.1029/2010WR009505.

Merz, R. - Blöschl, G. (2004) Regionalisation of catchment model parameters. Journal of Hydrology, (27), pp. 95-123. Doi: 10.1002/hyp. 6253 .

Nash, J. E. and Sutcliffe, J. V. (1991) River flow forecasting through conceptual models, part I- a discussion of principles. Journal of Hydrology, 10, pp. 282-290. Doi: 10.1016/00221694(70)90255-6.

Oudin, L. - Perrin, Ch. - Mathevet, T. - Andréassian, V. Miechel, C. (2006) Impact of biased and randomly corrupted inputs on the efficiency at the parameters of watershed models. Journal of Hydrology, 320, pp. 62-83. Doi: 10.1016/j. jhydrol.2005.07.016.

Parajka, J. - Merz, R. - Blöschl, G. (2007) Uncertainty and multiple calibration in regional water balance modelling case study in 320 Austrian catchments. Hydrol. Process, (21), pp. 435-446. Doi: 10.1002/hyp.6253.

Swagatam, D. - Ponnuthurai, N.S. (2011) Diferential evolution: A survey of the State-of-the-Art. Transactions on evolutionary computation, Vol. 15, No.1, pp. 4-31. Doi: 10.1109/ TEVC.2010.2059031.

Vaze, J. - Post, D. A. - Chiew, F. H. S. - Perraud, J. M. - Viney, N. R. - Teng, J. (2010) Climate nonnstationarity - Validity of calibrated rainfall-runoff models for use in climatic changes studies. J. Hydrol., 394(3-4), pp. 447-457. Doi:10.1016/j.jhydrol.2010.09.018.

Viglione, A. and Parajka, P. (2014) TUW model: Lumped hydrological model for educational purposes. Version 0.1-4.

Wilby, R. (2005) Uncertainty in water resource model parameters used for climate change impact assessment. Hydrol. Processes, 19, pp. 3201-3219. Doi:10.1002/hyp.5819. 